\title{
Male Perpetrators of Intimate Partner Violence: Support for Health Care Interventions Targeted at Level of Risk
}

\author{
Karin V. Rhodes' and Theodore J. Iwashyna ${ }^{2}$ \\ ' Department of Emergency Medicine, School of Medicine and School of Social Policy and Practice, \\ University of Pennsylvania, United States of America \\ ${ }^{2}$ Department of Pulmonary Critical Care, School of Medicine. University of Michigan, \\ United States of America
}

\begin{abstract}
The mental health correlates of male aggression or violence against an intimate partner (IPV) are examined using exploratory cluster analysis for 81 men who selfreported risk factors for IPV perpetration on a computer-based health risk assessment. Men disclosing IPV perpetration could be meaningfully subdivided into two different clusters: a high pathology/high violence cluster, and lower pathology/low violence cluster. These groups appear to perpetrate intimate partner violence in differing psychoemotional contexts and could be robustly identified using multiple distinct analytic methods. If men who self-disclose IPV in a health care setting can be meaningfully subdivided based on mental health symptoms and level of violence, it lends support for potential new targeted approaches to preventing partner violence perpetration by both women and men.
\end{abstract}

Keywords: male intimate partner violence perpetration, risk assessment, urban mental health

Intimate partner violence (IPV) is a major source of morbidity and mortality, with one in six US couples experiencing physical assault in the past year. While women perpetrate an equal amount of abuse as men (Straus \& Gelles, 1990; Schafer, Caetano, \& Clark, 1998), it is generally acknowledged that they suffer the majority of adverse physical and mental health consequences (Bachman \& Salzman, 1995; Sutherland, Bybee, \& Sullivan, 1998; Cascardi, Langhinrichsen, \& Vivian, 1992; Vivian \& Langhinrichsen-Rohling, 1994; Smith, Thornton, DeVellis, Earp, \& Coker, 2002).

National Crime Victimization Survey (NCVS) data indicate that there was an estimated 688,350 nonfatal incidents of IPV in 2004, yielding an incidence rate of 3.8 per 1000 women and 1.0 per 1000 men (Catalano, McGrath, Ramisetty-Mikler, $\&$ Field, 2005). Due to underreporting, this is likely an underestimate of the magnitude of the problem. The last population-based survey designed specifically to identify IPV reported an annual incidence of IPV victimisation that was 50 percent higher for females and more than twice as high for males as that reported in the NCVS (Tjaden \& Thoennes, 1998). The health consequences of IPV include high rates of injury, chronic pain, anxiety, depression, somatic concerns, and substance

Address for correspondence: Karin V. Rhodes, Director, Division of Health Care Policy Research, Department of Emergency Medicine, School of Social Policy and Practice, 3815 Walnut, Rm 201, University of Pennsylvania, 215-421-1036,USA.E-mail: kur@sp2.upenn.edu 
abuse (Campbell, 2002; Stein \& Kennedy, 2001; Coid, Petruckevitch, Chung, Richardson, Morrey, \& Feder, 2003). Research suggests that failure to address psychological and physical abuse in both genders can lead to deterioration in mental and physical health over time (Felitti et al., 1998; Coker et al., 2002). Intimate partner violence also interferes with employment productivity (Swanberg, Logan, \& Macke, 2005). Recent figures estimate the total cost of IPV for medical care, mental health services, and lost time from work due to injury and death at US\$8.3 billion (Centers for Disease Control and Prevention, 2003; Max, Rice, Finkelstein, Bardwell, \& Leadbetter, 2004; Coker, Reeder, Fadden, \& Smith, 2004).

Interventions for male perpetrators of violence against women have traditionally targeted one of two groups of men. On the one hand they have attempted to reform 'batterers' after those men were identified through the criminal justice system or via a female partner's flight to a shelter. On the other hand, there have been bold efforts to reform gender role expectations and conflict resolution styles aimed at the entire population. Although both interventions are important, from the perspective of reducing victimisation, neither intervention is perfect. Working with court-mandated perpetrators of partner violence, by definition, occurs after they have engaged in severe violence; it is aimed at the prevention of further significant harm. General population interventions, in contrast, are likely to expend resources on large numbers of people who would not, in the current cultural context, have been physically abusive towards their loved ones. A third approach would be to identify a population of both men and women that is at higher risk for committing partner violence, but in which violence has not yet reached the threshold of law enforcement involvement. Although women perpetrate an equal amount of abusive behaviours as men (Tjaden \& Thoennes, 1998) and women's perpetration of IPV puts them at higher risk of victimisation (Stith, Smith, Penn, Ward, \& Tritt, 2004), the current study focuses on male perpetrators of IPV, as this group has been addressed in a very monolithic manner (Corvo \& Johnson, 2003) within the criminal justice setting, as opposed to the health care setting.

While the emphasis of IPV screening in health care settings has been targeted at identification of women victims, there is ample evidence that male victims and perpetrators are also being seen in health care settings and that men disclosing IPV victimisation also have high rates of perpetration (Chelmowski \& Hamberger, 1994; Mechem, Shofer, Reinhard, Hornig, \& Datner, 1991; Coben \& Friedman, 2002). Unfortunately, there has been a notable lack of studies on screening or attempts to intervene with IPV-involved men in health care settings. Currently, the vast majority of interventions for IPV-involved men focus on male perpetrators and occur through court-mandated treatment programs, where interventions are framed as punitive and isolating legal remedies. In general, these programs use a one-size-fitsall model of group didactics and cognitive restructuring (Pence \& Paymar, 1993) that has shown little evidence of effectiveness when widely applied (Babcock, Green, \& Robie, 2004). However, data from batterer's treatment, perpetrator typology research, marital therapy and substance abuse treatment programs have identified that there are subsets of perpetrators for whom specific tailored treatment may be more effective (Dutton \& Golant, 1995; Holzworth-Munroe \& Stuart, 1994) particularly for those with co-occurring substance abuse (Fals-Stewart \& Kennedy, 2005; O'Farrell, Murphy, Stephan, Fals-Stewart, \& Murphy, 2003). This has implications for individually-tailored perpetrator interventions targeted at their level of risk and co-morbid conditions (Schumacher, Fals-Stewart, \& Leonard, 2003; 
Cavanaugh \& Gelles, 2005). However, current policies continue to be based on simplistic models of unidirectional, unidimensional understanding that belies the complexities of human relationships (Miller, 1994).

A population of men who self-disclose IPV perpetration in a health care setting is potentially more amenable to behaviour change, as they are at an earlier stage in their development of socially unsanctioned behaviour; they are at the beginning of what sociologist might call their 'deviance careers' (Becker, 1991, 1963; Goffman, 1963). But, at the same time, these men may have already engaged in some aggressive behaviour, and, therefore, clearly show an increased potential for partner violence.

Some higher risk individuals might be reached by screening for partner violence perpetration in the health care setting. Among men in a batterers' treatment program, $46 \%$ said they had seen a doctor in the last 6 months; the Emergency Department (ED) was the most common site (Coben \& Friedman, 2002). Ernst, Nick, Weiss, Houry, \& Mills (1997) found that $13 \%$ to $30 \%$ of men in various ED samples report current physical intimate partner violence victimisation and men who report being physically abused are at higher risk for perpetrating violence themselves (Ernst, Nick, Weiss, Houry, \& Mills, 1997; Mechem et al., Mills, Mills, Taliaferro, Zimbler, \& Smith, 2003). Lipsky, Caetano, Field, \& Bazargan (2004) found that $15 \%$ of men in a symptom-based consecutive sample in an urban emergency room self-reported current intimate partner violence perpetration (Lipsky et al., 2004). This group included $17.1 \%$ of coloured men and $9.1 \%$ of Hispanic male patients in a Los Angeles Emergency Department (Lipsky, Caetano, Field, \& Bazargan, 2005).

Outside the health care system, there may be few other points of contact for adult men with social institutions perceived as interested in helping them. Well intentioned law enforcement policies (e.g., mandatory arrest) have been shown in multiple randomised trials to actually increase levels of violence in some important subpopulations such as unemployed minority men who place less stake on conformity (Berk, Campbell, Klap, \& Western, 1992; Pate \& Hamilton, 1992; Sherman, Smith, Schmidt, \& Rogan, 1992), and the law enforcement agencies may not be permitted to tailor their responses based on those characteristics known to influence revictimisation rates.

Similarly, studies of follow-up visits for domestic disturbance calls by social workers (so-called 'second responders') have shown mixed effects, again with the possibility of interventions increasing some women's risk of severe violence (Greenspan et al., 2005). The fundamentally adversarial nature of the criminal justice system may not be optimal for achieving the early attitude change necessary to prevent further intimate partner violence. In contrast, there have been several relatively successful efforts at using the health care system to deal with social problems. Hazardous drinking, alcohol-related injury, and drug use have been reduced by pointing out the medical risks to individuals of engaging in these behaviours .(Bien, Miller, \& Tonigan, 1993; Fleming et al., 2002, McCambridge \& Strang, 2004) More germanely, the health care system has been able to reduce risks individuals pose to others, e.g., child safety (Zaza, Sleet, Thompson, Sosin, \& Bolen, 2001) and safe sex problems (Richardson et al., 2004). The therapeutic alliance between patients and physicians may be effective at prompting early behavioural change.

Once the health care system identifies men at 'increased risk' of serious IPV (whether it be victimisation, perpetration, or both) then some services need to be provided to them. A prerequisite to such service provision is through understanding 
the population identified. Several scholars have insightfully argued for the importance of drawing distinctions among perpetrators of domestic violence (Johnson $\&$ Ferraro, 2000), indeed, of deconstructing the monolithic notion of 'the batterer' (Corvo \& Johnson, 2003). Thus, Holzworth-Munroe and colleagues have distinguished between four groups in predominantly clinical samples: family-only, low-level antisocial, borderline dysphoric, and generally violent antisocial (Holzworth-Munroe \& Meehan, 2004; Holzworth-Munroe, Meehan, Herron, Rehman, \& Stuart, 2000). Again with attention to clinical samples of men, Cavanaugh and Gelles (2005) distinguish low, medium and high-risk batterers. Johnson, theorising intercouple dynamics, distinguishes situational couple violence from intimate terrorism (Johnson, 1995, 1999; Johnson \& Leone, 2005). None of these divisions is necessarily applicable to men who identify themselves in the health care setting.

To that end, we sought examine diversity of risk among a fairly homogenous group of urban men who identified themselves as perpetrators of IPV in an urban health care setting.

\section{Methods}

\section{Study Framework and Respondent Recruitment}

We approached sequential nonemergent male patients presenting to an urban ED by order of most recently arrived for participation in a computer-based health questionnaire (Promote Health). Eligible patients were 18 to 55 years old, English speaking, and not overtly psychotic or obviously under the influence of drugs or alcohol. Research assistants recruited participants from the ED waiting room during a convenience sample of data collection periods between 7 a.m. and 11 p.m., Monday through Sunday. As part of the informed consent process, patients were told that the Promote Health questionnaire asked about lifestyle and behavioural health risks, and based on their answers they would receive health advice and the results would also be shared with the treating physician. While they were free to withdraw from the study at any point, they were told that if there was any concern about harm to themselves or others, the research assistant would need to bring this information to the attention of the treating physician.

After completing the Promote Health computer questionnaire and without reference to their responses, a convenience sample of patients was approached for further participation. They were asked if they would complete an additional booklet comprising validated questionnaires (about 300 questions) to help us with questionnaire development. The booklet was presented in paper and pencil format; patients were compensated with US\$20 cash before leaving the ED. We report here on 81 men who self-reported intimate partner violence perpetration in Promote Health and also completed all the questionnaires.

\section{Computer-based Survey (Promote Health)}

The Promote Health questionnaire requires a 5 th grade reading level and is taken on a touch screen computer in private, away from any family members or friends to ensure confidentiality and enhance patient disclosure in sensitive areas. The development of Promote Health has been discussed in detail elsewhere (Rhodes, Lauderdale, He, Howes, \& Levinson, 2002; Rhodes et al., 2001). In brief, the Promote Health questions were developed by experienced emergency physicians 
and internists incorporating previously validated questions whenever possible. The overall questionnaire is framed as a health risk assessment and asks questions about a variety of health risks (e.g., asthma, hypertension, smoking); however, it has an emphasis on mental health, social support, intimate partner violence and sexual risks, because these are less likely to be included in a standard clinical interview. To assess the readability, content and construct validity of our partner violence screening questions the questionnaire was tested using cognitive interviews (Sudman, Bradburn, \& Schwarz, 1995) with over 140 urban male and female ED patients prior to the current study. It took the average male patient approximately $10 \mathrm{~min}$ utes to complete. Based on their answers to the survey, the patient receives health recommendations, or suggestions about what they can do to improve their health and referrals to appropriate health or community resources. The treating physician receives a one page summary of the patient's demographics, and major health risks. There is a 'Physician to Assess Risks' box that is generated to alert the physician of any patient responses that may indicate current danger, such as symptoms of major depression or suicidal ideation and potential for emotional or physical abuse in an intimate relationship. Any risk of IPV or symptoms of major depression or suicidal ideology was also brought to the attention of the treating physician by the research assistant as soon as possible for their further assessment of any potential for danger.

We identified the sample of 81 men at risk of being possible perpetrators of IPV based on an affirmative response to any of the following questions:

- 'When you get angry, do you ever hit/push/shove your partner?'

- 'Are you worried you might physically hurt your partner?'

- 'Have you ever physically hurt your partner?'

- 'Have you ever made your partner have sex when he/she didn't want to?'

We then performed exploratory cluster analysis of their responses to a set of validated scales (described below), to examine whether meaningful distinct subgroups exist among these men. Of note, these men all self-reported behaviour that they are likely to have known would be viewed as unacceptable by the health care system to which they were reporting.

\section{Scales}

Several well-known validated measurement scales were use to further explore the characteristics of self-reported perpetrators of intimate partner violence. These were administered as separate booklets.

Six tools were used to measure comorbid psychological functioning, including: Zung's Self-administered Depression Scale (Zung, Richards, \& Short, 1965), Spielberger's Anger Expression Index (Spielberger, Sydeman, Owen, \& Marsh, 1999), two of Eysenck's Impulsivity Subscales (Impulsiveness and Empathy), (Eysenck \& Eysenck, 1991), the Quality of Life Experiences and Satisfaction Questionnaire (Q-LES-Q) (Endicott, Nee, Harrison, \& Blumenthal, 1993), and Spielberger's Trait Anxiety Index (Barnes, Harp, \& Jung, 2002; Spielberger, 1983).

Comorbid alcohol and drug use were measured in several ways. Questionnaires included the Drug Abuse Screening Test (DAST) (Gavin, Ross, \& Skinner, 1989), and the Brief Michigan Alcoholism Screening Test (MAST) (Seltzer, Vinokur, \& Van Rooijen, 1975). Within Promote Health, standard CAGE screening questions were asked, as well as questions about frequency of alcohol use, drug use, and unprotected sex. 
Two scales specifically addressed violent or aggressive behaviour and partner abuse: the Revised Conflict Tactics Scale (CTS2) (Straus, Hamby, Boney-McCoy, $\&$ Sugarman, 1996) and Life History of Aggression (LHA) (Coccaro, Berman, \& Kavoussi, 1997). The CTS2 measures how persons in a marital, cohabiting, or dating relationship deal with conflict, and measures the occurrence of specific psychological and physical acts. It also assesses the use of negotiation to deal with conflicts in these relationships. The scale consists of 39 paired items that are designed to ask about the behaviour of both the participant and the partner. Therefore, there are two questions for each item totalling 78 questions. The 39 items separate into five subscales: 1) Negotiation, 2) Physical Assault, 3) Psychological Aggression, 4) Sexual Coercion, and 5) Injury, and there are minor and severe subscales for the Physical Assault, Psychological Aggression, Sexual Coercion and Injury subscales. Life History of Aggression uses self-reported frequencies to measure three domains: overall aggression, self-directed aggression, and antisocial aggression.

\section{Cluster Analytic Methods}

Agglomerative methods were used to develop the initial clustering (Aldenderfer $\&$ Blashfield, 1984). Intuitively, agglomerative methods act by comparing all possible pairs of individuals, and linking the two who are closest to each other on all the variables included. This pair is then compared to all other individuals. If two other individuals are closer to each other than they are to the initial pair, they are combined as a separate group; if an individual is found who is closer to the existing pair than to any other individual, that individual is then linked into the group. This pro-

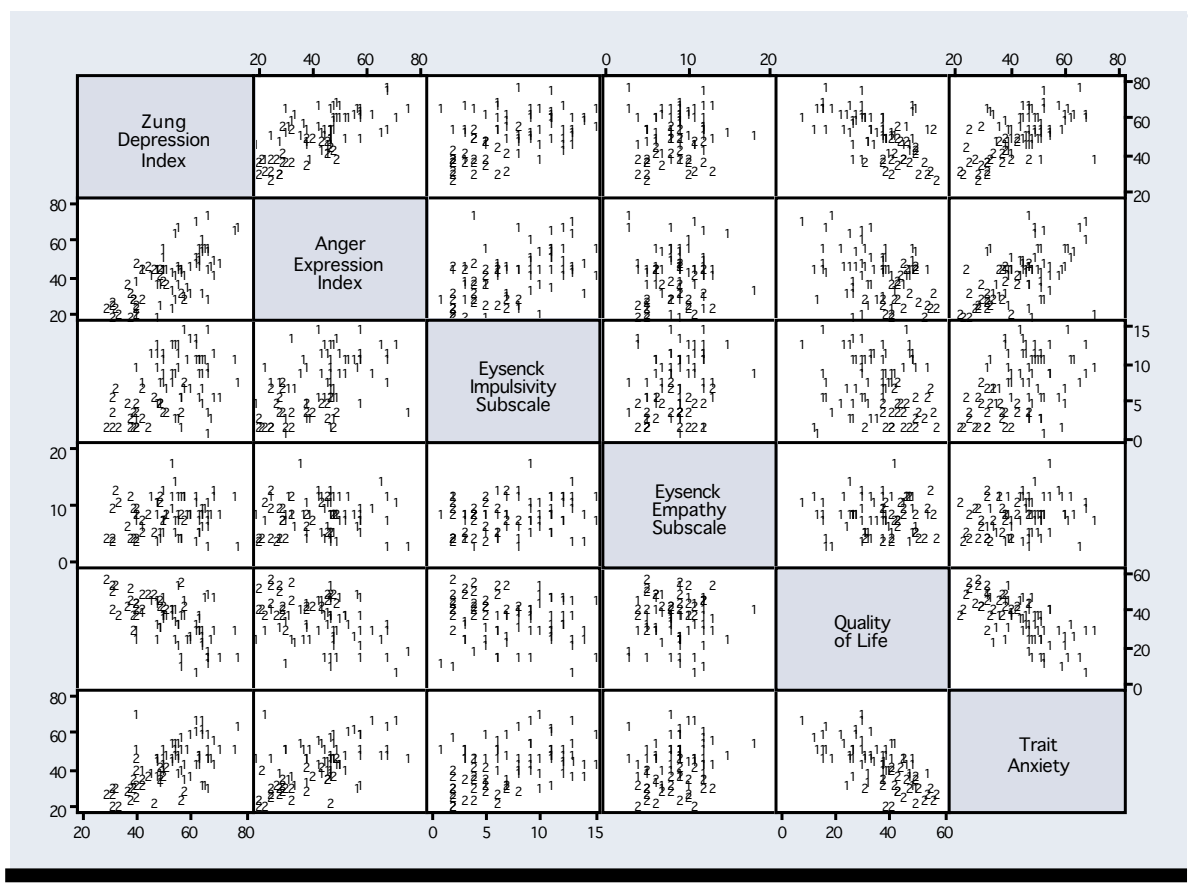

\section{FIGURE 1}

Differentiation of groups on clustering variables. 


\section{TABLE 1}

Self-Reported Intimate Partner Violence $(N=81)$

\begin{tabular}{lcc} 
& $n \quad \begin{array}{c}\% \text { of all } \\
\text { screened } \\
\text { men }\end{array}$ \\
\hline When you get angry, do you ever hit/push/shove your partner? & 57 & 24.4 \\
Are you worried you might physically hurt your partner? & 19 & 8.1 \\
Have you ever physically hurt your partner? & 20 & 8.5 \\
Have you ever made your partner have sex when he/she & & 8.5 \\
didn't want to? & 20 & 8
\end{tabular}

cess is repeated until all individuals are assigned to a group, and finally until all groups are linked to each other.

In this application, all clustering variables were standardised to span the range of 0 to 1 (Everitt, Landau, \& Leese, 2001). Euclidian distance was then calculated. Visual inspection of the dendrogram was used to divide it into groups; divisions were only made at clear levels. Perfect concordance in group assignment was obtained using either Ward's linkage or complete linkage (Ward, 1963). Eighty-five per cent of respondents were placed in the same group when average linkage was used. K-means linkage with two groups produced $88 \%$ identical groupings. We present the complete/Ward's linkage grouping results here.

All variables are untransformed unless otherwise indicated. Stata 8.2 was used for all analyses and $p$ values are presented without adjustment for multiple compar-

\section{TABLE 2}

Demographics of Perpetrators Sample

\begin{tabular}{lcc}
\hline & Mean & $S D$ \\
\hline Age (years) & 33.83 & 9.91 \\
Race is African-American & 0.95 & \\
Employed & 0.58 & \\
At least high school degree & 0.73 & \\
Married & 0.20 & \\
In a relationship & 0.77 & \\
Lives alone & 0.15 \\
Very good or excellent health & 0.30 \\
& & \\
At risk drinking & 0.37 & \\
Smokes & 0.63 & \\
Recent street drug use & 0.32 & \\
Risky sexual behaviour & 0.12 & \\
Social support & 3.73 & \\
Ever in a knife or gun fight & 0.38 & \\
Has access to a gun & 0.35 & \\
\hline
\end{tabular}


TABLE 3

Differences Between Groups on Clustering Variables

\begin{tabular}{lrrrrr}
\hline & \multicolumn{3}{c}{$\begin{array}{c}\text { Group } 1 \\
(n=56)\end{array}$} & \multicolumn{2}{c}{$\begin{array}{c}\text { Group 2 } \\
(n=25)\end{array}$} \\
& \multicolumn{1}{c}{ Mean } & \multicolumn{1}{c}{$S D$} & Mean & \multicolumn{1}{c}{$S D$} & $p$ \\
\hline Zung Depression & 57.52 & 8.50 & 41.00 & 7.83 & $<.001$ \\
Anger Expression Index & 46.48 & 12.25 & 32.28 & 9.40 & $<.001$ \\
Eysenck Impulsivity — Impulsive Subscale & 8.88 & 3.51 & 4.00 & 1.83 & $<.001$ \\
Eysenck Impulsivity — Empathy Subscale & 8.91 & 3.01 & 8.04 & 2.72 & .204 \\
Quality of Life & 32.07 & 10.71 & 45.68 & 6.47 & $<.001$ \\
Trait Anxiety & 49.23 & 9.13 & 32.72 & 6.71 & $<.001$ \\
\hline
\end{tabular}

isons. Nonetheless, readers are reminded that very large numbers of comparisons are being tested, and even more than usual caution should be used when considering conventional thresholds of statistical as opposed to clinical significance.

\section{Results}

\section{Perpetrators Sample}

This sample of self-reported perpetrators of physical intimate partner violence was drawn from the nonurgent cases presenting to a single inner city urban Emergency Department. Their self-reported behaviours are shown in Table 1. The sample consists of relatively young (mean age 33.8 years) and 95\% were African-American. They engaged in a degree of risky behaviour, including drinking, smoking, using street drugs, and having access to firearms (see Table 2).

\section{Clustering Results}

The basic clustering results are shown in Figure 1. Fifty-six men were assigned to group 1; 25 men were assigned to group 2. In this matrix graph, the six clustering variables are presented, with scatter plots of all two-way combinations. The cluster to which each individual was assigned is indicated. The cluster structure of the highly dimensional data is made clear with labelling as it might not be clear from the raw scatter plots (low pathology individuals on any pairwise trait comparison are consistently low pathology, despite the relatively modest overall correlations between the different scales). These differences are shown numerically in Table 3, which presents the differences in mean values for the two clusters. The high degree of statistical significance in this table is uninformative because the groups were, after all, constructed precisely to maximise the spread between the two groups on these six variables.

\section{Diversity of Violence among Perpetrators of Intimate Partner Violence}

The two groups displayed quite different approaches to violence in their relationships, as shown in Table 4. In contrast to Table 3, the significant differences between the two groups of men in Table 4 were not predetermined by the clustering algorithm. As shown, the group 1 'high pathology' men displayed higher levels of violence across the board in the Conflict Tactics Scale 2 subscales. They report 
TABLE 4

Diversity of Violence

\begin{tabular}{|c|c|c|c|c|c|}
\hline & \multicolumn{2}{|c|}{ Group 1} & \multicolumn{2}{|c|}{ Group 2} & \multirow[b]{2}{*}{$p$} \\
\hline & Mean & $S D$ & Mean & $S D$ & \\
\hline \multicolumn{6}{|l|}{ CTS2 - Answering for Self } \\
\hline Negotiation - Emotion & 24.29 & 20.49 & 30.96 & 28.71 & 0.301 \\
\hline Negotiation - Cognitive & 19.21 & 18.36 & 20.64 & 22.36 & 0.781 \\
\hline Psychological Aggression - Minor & 24.75 & 26.95 & 9.60 & 12.32 & 0.001 \\
\hline Psychological Aggression - Severe & 7.11 & 14.75 & 1.20 & 2.65 & 0.005 \\
\hline Physical Aggression - Minor & 9.00 & 12.66 & 1.12 & 2.54 & 0.000 \\
\hline Physical Aggression - Severe & 5.73 & 11.69 & 0.32 & 0.90 & 0.001 \\
\hline Sexual Coercion - Minor & 7.04 & 13.81 & 6.24 & 11.46 & 0.788 \\
\hline Sexual Coercion - Severe & 3.29 & 9.25 & 0.04 & 0.20 & 0.011 \\
\hline Injuries - Minor & 1.82 & 4.86 & 0.44 & 1.08 & 0.048 \\
\hline Injuries - Severe & 2.27 & 6.11 & 0.00 & 0.00 & 0.007 \\
\hline \multicolumn{6}{|l|}{ CTS2 - Answering for Partner } \\
\hline Negotiation - Emotion & 22.95 & 19.40 & 27.80 & 26.79 & 0.420 \\
\hline Negotiation - Cognitive & 16.38 & 17.32 & 19.24 & 22.38 & 0.573 \\
\hline Psychological Aggression - Minor & 22.21 & 25.46 & 9.92 & 11.45 & 0.004 \\
\hline Psychological Aggression - Severe & 7.34 & 13.08 & 0.64 & 1.66 & 0.000 \\
\hline Physical Aggression - Minor & 10.52 & 15.85 & 4.28 & 9.59 & 0.032 \\
\hline Physical Aggression - Severe & 6.05 & 12.62 & 0.44 & 1.16 & 0.002 \\
\hline Sexual Coercion - Minor & 5.09 & 10.18 & 6.16 & 11.43 & 0.689 \\
\hline Sexual Coercion - Severe & 2.64 & 7.52 & 0.12 & 0.44 & 0.015 \\
\hline Injuries - Minor & 1.71 & 4.13 & 0.24 & 0.66 & 0.012 \\
\hline Injuries - Severe & 1.71 & 5.27 & 0.00 & 0.00 & 0.018 \\
\hline \multicolumn{6}{|l|}{ Life History of Aggression } \\
\hline Aggression Subscale & 11.52 & 6.60 & 8.16 & 5.61 & 0.022 \\
\hline Self-Directed Aggression Subscale & 1.00 & 1.69 & 0.44 & 1.29 & 0.109 \\
\hline Antisocial Behaviour Subscale & 6.96 & 4.62 & 4.64 & 4.21 & 0.031 \\
\hline
\end{tabular}

these higher levels both for themselves and their partner. Of the physical violence subscales, only minor sexual coercion did not vary, and most of these differences are highly significant at conventional levels, even after adjustment for multiple comparisons. Similarly, the group 1 high pathology men showed higher levels of aggression on two of the three LHA subscales.

The two groups of men displayed two areas of marked similarity. Their negotiation tactics are quite similar, despite very disparate levels of violence. They also share a lack of self-destructive aggression, despite their varying levels of depression.

\section{Similarities in Socio-Economic and Drug and Alcohol Background}

The men in the two groups exist in quite similar socioeconomic situations. As shown in Table 5, they are the of same age, employment status, education level, relationship 
TABLE 5

Similarity of Background and Other Behaviour

\begin{tabular}{lccccc} 
& \multicolumn{3}{c}{ Group 1 } & \multicolumn{2}{c}{ Group 2 } \\
\hline & Mean & $S D$ & Mean & $S D$ & $p$ \\
\hline Age (years) & 34.48 & 10.02 & 32.36 & 9.72 & 0.373 \\
Race is African-American & 0.95 & & 0.96 & 0.795 \\
Employed & 0.57 & & 0.60 & 0.810 \\
At least high school degree & 0.68 & 0.84 & 0.131 \\
Married & 0.20 & 0.20 & 0.970 \\
In a relationship & 0.71 & 0.88 & 0.104 \\
Lives alone & 0.18 & & 0.08 & 0.249 \\
Very good or excellent health & 0.18 & & 0.56 & 0.001 \\
& & & & & \\
At risk drinking & 0.43 & & 0.24 & 0.105 \\
Smokes & 0.66 & & 0.56 & 0.386 \\
Recent street drug use & 0.36 & & 0.24 & 0.297 \\
Risky sexual behaviour & 0.16 & & 0.04 & 0.127 \\
Social support & 3.54 & 1.26 & 4.16 & 1.18 & 0.112 \\
Ever in a knife or gun fight & 0.45 & & 0.24 & 0.078 \\
Has access to a gun & 0.38 & & 0.28 & 0.406 \\
\hline
\end{tabular}

Note: $p$-value is for $t$-tests for age, the only continuous variable; $p$-values were for $\chi^{2}$ tests for all other categorical variables.

status, and social support level. They engage in similar levels of risky alcohol, cigarette, and street drug use. They are equally like to have risky sexual relations, and to have access to a gun. Although not statistically significant, the group 1 high psychopathology individuals are more likely to have been in a knife or gun fight, consistent with their higher levels of violence. The only significant difference between the two groups is in their self-rated health, where the high psychopathology individuals are much less likely to report 'very good' or 'excellent' health.

\section{Failure of Other Clustering Variables}

Using the same set of agglomerative clustering methods, we examined several other domains for emergent structure. We looked within a complex of drug, alcohol and sexual history risk behaviours, as well as on socioeconomic and demographic factors. In neither of these two domains was there compelling evidence of cluster structure by inspection of the dendrograms or use of the $k$-means procedures with stopping rules.

\section{Discussion}

Within an urban Emergency Department, our results suggest that men who are physically aggressive with their partner may be meaningfully subdivided into two quite different clusters: a high pathology/high violence cluster, and lower pathology/low violence cluster. These groups appear to perpetrate intimate partner violence in different psychoemotional contexts, and with different styles. These groups could be robustly identi- 
fied in our data using multiple distinct analytic methods. However, the groups could not be differentiated on the basis of demographics or participation in other 'medically high risk' behaviours.

\section{Comparison to Other Typologies}

There are analogies between our clustering and other proposed clinical subdivisions. Working in a much more psychological milieu, Holzworth-Munroe and colleagues have distinguished between four groups in predominantly clinical samples: familyonly, low-level antisocial, borderline dysphoric, and generally violent antisocial (Holzworth-Munroe \& Meehan, 2004; Holzworth-Munroe et al., 2000). However, in their pioneering longitudinal work, several of these distinctions were found to be less robust and persistent. Importantly, this typology was designed for use by mental health clinicians with a primary focus on intimate partner violence. For medical professionals with a wider purview, a more 'rough and ready' distinction may be more practical.

One step toward such a pragmatic division is Cavanaugh and Gelles' (2005) simplification of batterers into low, medium and high-risk groups. They argue that there is, in practice, a clinical spectrum of behaviour, and that empirically useful divisions can separate groups that are similar enough to make meaningful treatment choices. Their synthetic piece provides no empirical data. We build on this, and find that division of the spectrum into two groups may be sufficient, and more accurately reflect the data.

The distinctions in our data do not map cleanly onto those distinctions drawn by Johnson in a seminal series of papers. What might be termed 'the Johnson hypothesis' is an analysis of couple-level interactions: that observed patterns of intimate partner violence emerge from the dynamic interaction of two individuals' approaches to marital problem-solving, gender relations, and power sharing in a particular sociological context. The distinction between situational (or common) couple's violence and intimate (or patriarchical) terrorism is a difference not only between a given man's predisposition to use violence or not, but also a function of his partner's ability to repel that violence, and a local community's sanctioning of that violence. For medical professionals, much of that function is beyond the scope of easy assessment; instead, an individual analysis seems likely to be more useful.

\section{Implications for Treatment}

The present two-group distinction suggests useful implications for therapy. Following Cavanaugh and Gelles, simple tailoring may be possible. The low pathology/low violence group may be amenable to a simple directed intervention. As their deviance careers are in an early stage, simple reorientation by physicians may be practical. A brief two minute intervention by physicians has been shown in randomised controlled trials to significantly improve cigarette quit rates (Law \& Tang, 1995). An analogous brief, normative intervention by medical professionals may be effective in reducing intimate partner violence in appropriately selected group 2 patients, particularly as it will often occur in the context of the professionals solving some other presenting problem for the patient in question.

It is worth noting at this point an unexpected strength of the medical profession in this context. The medicalisation of social problems - an affinity for decontextualisation and personalisation of broader sociological problems - has been repeatedly derided. In this context, it may be of tactical use. Indeed, it is probably 
unreasonable to ask physicians and patients to regularly cover gender theory, psychodynamics and power relations in the context of a single health care encounter. Instead a brief, behaviour-focused intervention, such as that proposed by Miller and Rollnick (1991), which in an IPV intervention would involve treating both victimisation and perpetration of physical and emotional abuse as seriously unhealthy behaviours, could fit well within the schemas both parties have for their interaction.

In contrast, group 1 patients seem at much higher risk for interventions leading to paradoxical increased levels of violence. The possibility of an inadequate, or even inflammatory, intervention by a physician with too little training and time seems real for this group. Therefore, the ability to make distinctions between low and high risk (a concept easily understood by medical providers) will be critical. However, careful attention will need to be given to studying system responses and the safety and effectiveness of prompt intervention by trained social workers or other mental health professionals. Further, customisation to specific neighborhood, socioeconomic and demographic characteristics seems important for this high pathology/high violence group.

\section{The Need for Prospective Validation and Other Conclusions}

Before firm practice recommendations on the differential treatment of the two groups can be made, further study is needed. As Holzworth-Monroe and Meehan(2004) showed, rigorously developed intellectually elegant typologies may not reflect reality as it actually plays out. Indeed, our previous findings with IPVinvolved men (Rhodes et al., 2009) would have suggested the level of IPV risk could have also been predicted by the level of other 'medically high risk' behaviours such as smoking, alcohol abuse, use of street drugs, or sexually high risk behaviours, in addition to the current mental health distinctions. So this typology clearly warrants further investigation. If our typology purports to say something about stable differences between the two groups of men, two conditions need to be met. First, practical sorting algorithms to divide the two groups need to be identified and replicated. Second, the robustness of these sortings across time needs to be demonstrated. Following these preconditions, the effectiveness of typology-based differential treatment needs to be studied.

This initial exploration suffers from the usual limitations of a hypothesis generating effort. Data from a convenience sample at a single site are of unproven generalisability. In particular, there is no reason to suspect that group 1 are truly twice as common as group 2 men; the two group's relative prevalences (although not the distinction between them) may be an artefact of the ways in which emergency department patients were recruited into the study. Importantly, we have not validated patient self-report of violence against some gold standard observation of these men's behaviour, such as a partner report. It is likely that some perpetrators were misclassified as nonviolent, and others reported 'worse' violence than might be objectively described to them.

Nonetheless, our study offers hope for an additional approach in the treatment of intimate partner violence. It reinforces the fact that men will self-identify themselves as perpetrators of intimate partner violence in a health care setting. It shows that a range of violence patterns exist, and that they can be meaningfully subdivided. It offers hope that groups amenable to simple versus more intensive interventions can be identified, offering a prospective effort to prevent violence in a focused and potentially cost effective way. 


\section{Acknowledgments}

The authors wish to acknowledge the many people who have contributed to conceptualising or collecting the data for this project, particularly Emil Cocarro, Zeenat Kahn, Naomi Levinthal, and Laura McCloskey. Karin Rhodes, MD is supported by a grant from NIMH \# K23 MH64572.

\section{References}

Aldenderfer, M.S., \& Blashfield, R.K. (1984). Cluster analysis. Newbury Park, CA: Sage.

Babcock, J.C., Green, C.E., \& Robie, C. (2004). Does batterers' treatment work? A meta-analytic review of domestic violence treatment. Clinical Psychology Review, 23(8), 1023-1053.

Bachman, R., \& Salzman, L.E. (1995). Violence against women: Estimates from the redesigned study (BJS Publication No. 154-348). Washington, DC: US Department of Justice, Bureau of Justice Statistics.

Barnes, L.L.B., Harp, D., \& Jung, W.S. (2002). Reliability generalization of scores on the Spielberger State-Trait Anxiety Inventory. Educational and Psychological Measurement, 62(5), 603-618.

Becker, H. (1991 (1963)). Outsiders: Studies in the sociology of deviance. Glencoe, IL: Free Press.

Berk, R.A., Campbell, A., Klap, R., \& Western, B. (1992). The deterrent effect of arrest in incidents of domestic violence: A Bayesian analysis of four field experiments. American Sociological Review, 57(5), 698-708.

Bien, T.H., Miller, W.R., \& Tonigan, J.S. (1993). Brief interventions for alcohol problems: A review. Addiction, 88, 315-335.

Campbell, J. (2002). Health consequences of intimate partner violence. The Lancet, 359, 13311336.

Cascardi, M., Langhinrichsen, J., \& Vivian, D. (1992). Marital aggression: Impact, injury, and health correlates for husbands and wives. Archives of Internal Medicine, 152, 1178-1184.

Catalano, S.M. (2005). Criminal Victimization, 2004. Data from the National Crime Victimization Survey, Bureau of Justice Statistics, Office of Justice Programs. Washington, DC: US Department of Justice.

Cavanaugh, M.M., \& Gelles, R.J. (2005). The utility of male domestic violence offender typologies: New directions for research, policy and practice. Journal of Interpersonal Violence, 20(2), $155-166$.

Centers for Disease Control, National Center for Injury Prevention and Control (2003). Costs of intimate partner violence against women in the United States. Atlanta, GA: Centers for Disease Control and Prevention, United States Department of Health and Human Services.

Chelmowski, M., \& Hemberger, L.K. (1994). Screening men for domestic violence in your medical practice. Wisconsin Medical Journal, 93(12), 623-626.

Coben, J.H., \& Friedman, D.I. (2002). Health care use by perpetrators of domestic violence. Journal of Emergency Medicine, 22(3), 313-317.

Coid, J., Petruckevitch, A., Chung, W., Richardson, J., Morrey, S., \& Feder, G. (2003). Abusive experiences and psychiatric morbidity in women primary care attenders. British Journal of Psychiatry, 183, 332-339.

Coker, A., Davis, K.E., Arias, I., Desai, S., Sanderson, M., Brandt, H.M., \& Smith, P.H. (2002).

Physical and mental health effects of intimate partner violence for men and women. American Journal of Preventive Medicine, 23, 260-268.

Coker, A., Reeder, C., Fadden, M.K., \& Smith, P. (2004). Physical partner violence and Medicaid utilization and expenditures. Public Health Reports, 119, 557-567.

Coccaro, E.F., Berman, M.E., \& Kavoussi, R.J. (1997). Assessment of life history of aggression: development and psychometric characteristics. Psychiatry Research, 73, 147-157.

Corvo, K., \& Johnson, P.J. (2003). Vilification of the 'batterer': How blame shapes domestic violence policy and interventions. Aggression and Violent Behavior, 8, 259-281. 
Dutton, D.G., \& Golant, S.K. (1995). The batterer: A psychological profile. New York: Basic Books.

Endicott, J., Nee, J., Harrison, W., \& Blumenthal, R. (1993). Quality of Life Enjoyment and Satisfaction Questionnaire: A new measure. Psychopharmacolgy Bulletin, 29(2), 321-326.

Ernst, A.A., Nick, T.G., Weiss, S.J., Houry, D., \& Mills, T.J. (1997). Domestic violence in an inner-city ED. Annals of Emergency Medicine, 30(2), 190-197.

Everitt, B.S., Landau, S., \& Leese, M. (2001). Cluster analysis (4th ed.). London: Arnold.

Eysenck, H.J., \& Eysenck, S.B.G. (1991). Manual of the Eysenck Personality Scales (EPS Adult). Kent: Hodder and Stoughton.

Fals-Stewart, W., \& Kennedy, C. (2005). Addressing intimate partner violence in substance abuse treatment. Journal of Substance Abuse Treatment, 29, 5-17.

Felitti, V.J., Anda, R.F., Nordenberg, D., Williamson, D.F., Spitz, A.M., Edwards, V., et al. (1998). Relationship of childhood abuse and household dysfunction to many of the leading causes of death in adults: The Adverse Childhood Experiences (ACE) study. American Journal of Preventive Medicine, 14, 245-258.

Fleming, M.F., Mundt, M.P., French, M.T., Manwell, L.B., Stauffacher, E.A., \& Barry, K.L. (2002). Brief physician advice for problem drinkers: Long-term efficacy and benefit-cost analysis. Alcoholism: Clinical and Experimental Research 26, 36-43.

Gavin, D.R., Ross, H.E., \& Skinner, H.A. (1989). Diagnostic validity of the drug abuse screening test in the assessment of DSM-III drug disorders. British Journal of Addiction, 84(3), 301-307.

Goffman, E. (1963). Stigma: Notes on the management of spoiled identity. New York: Touchstone.

Greenspan, R., Weisburd, D., Lane, E., Ready, J., Crossen-Powell, S., \& Booth, W.C. (2005). Richmond's second responders: Partnering with police against domestic violence. Washington, DC: Police Foundation.

Holzworth-Munroe, A., \& Meehan, J. C. (2004). Typologies of men who are maritally violent: Scientific and clinical implications. Journal of Interpersonal Violence, 19(12), 1369-1389.

Holzworth-Munroe, A., Meehan, J. C., Herron, K., Rehman, U., \& Stuart, G. L. (2000). Testing the Holzworth-Munroe and Stuart (1994) Hypothesis. Journal of Consulting and Clinical Psychology, 68(6), 1000-1019.

Holzworth-Munroe, A., \& Stuart, G.L. (1994). Typology of male batterers: Three sub-types and the differences among them. Psychological Bulletin, 116, 476-497.

Johnson, M.P. (1995). Patriarchical terrorism and common couple violence: Two forms of violence against women. Journal of Marriage and the Family, 57(2), 283-294.

Johnson, M.P. (1999). Two Types of Violence Against Women in the American Family: Identifying Patriarchal Terrorism and Common Couple Violence. Paper presented at the National Council on Family Relations, Irvine, CA.

Johnson, M.P., \& Ferraro, K.J. (2000). Research on domestic violence in the 1990s: Making distinctions. Journal of Marriage and the Family, 62(4), 948-963.

Johnson, M.P., \& Leone, J.M. (2005). The differential effects of intimate terrorism and situational couple violence: Findings from the national violence against women survey. Journal of Family Issues, 26(3), 322-349.

Law, M. \& Tang, J.L. (1995). An analysis of the effectiveness of interventions intended to help people stop smoking. Archives Intern Med.,155,1933-1941.

Lipsky, S., Caetano, R., Field, C.A., \& Bazargan, S. (2004). Violence-related injury and intimate partner violence in an urban Emergency Department. Journal of Trauma-Injury Infection and Critical Care, 57, 352-359.

Lipsky, S., Caetano, R., Field, C.A., \& Bazargan, S. (2005). The role of alcohol use and depression in intimate partner violence among Black and Hispanic patients in an urban emergency department. American Journal of Drug and Alcohol Abuse, 31, 225-242.

Max, W., Rice, D., Finkelstein, E., Bardwell, R., \& Leadbetter, S. (2004). The economic toll of intimate partner violence against women in the United States. Violence and Victims, 19, 259272. 
McCambridge, J., \& Strang, J. (2004). The efficacy of single-session motivational interviewing in reducing drug consumption and perceptions of drug-related risk and harm among young people: results from a multi-site cluster randomized trial. Addiction, 99(1), 39-52.

Mechem, C.C., Shofer, F.S., Reinhard, S.S., Hornig, S., \& Datner, E. (1991). History of domestic violence among male patients presenting to an urban emergency department. Academic Emergency Medicine, 6(8), 786-791.

Miller, S.L. (1994). Expanding the boundaries: Toward a more inclusive and integrated study of intimate violence. Violence and Victims, 9, 183-194.

Miller, W.R., \& Rollnick, S. (1991). Motivational interviewing: Preparing people to change addictive behavior. New York: Guilford Press.

Mills, L.D., Mills, T.J., Taliaferro, E., Zimbler, A., \& Smith, D. (2003). The prevalence of femaleto-male intimate partner violence in an urban Emergency Department. Journal of Emergency Medicine, 25(2), 215-218.

O'Farrell, T.J., Murphy, C.M., Stephan, S.H., Fals-Stewart, W., \& Murphy, M. (2004). Partner violence before and after couples-based alcoholism treatment for male alcoholic patients: The role of treatment involvement and abstinence. Journal of Consulting and Clinical Psychology, 72, 202-217.

Pate, A. M., \& Hamilton, E. E. (1992). Formal and informal deterrents to domestic violence: The Dade County Spouse Assault Experiment. American Sociological Review, 57(5), 691-697.

Pence, E., \& Paymar, M. (1993). Education groups for men who batter: The Duluth Model. New York: Springer Publishing Company, Inc.

Rhodes, K.V., Lauderdale, D.S., He, T., Howes, D.S., \& Levinson, W. (2002). Between me and the computer: Increased detection of intimate partner violence using a computer questionnaire. Annals of Emergency Medicine, 40(5), 476-484.

Rhodes, K.V., Lauderdale, D.S., Stocking, C.B., Howes, D.S., Roizen, M.F., \& Levinson, W. (2001). Better health while you wait: A controlled trial of a computer-based intervention for screening and health promotion in the emergency department. Annals of Emergency Medicine, 37(3), 284-291.

Rhodes, K.V., Houry, D., Cerulli, C., Straus, H., Kaslowe, N., \& McNutt, L.A. (2009) Intimate partner violence and co-morbid mental health conditions among urban male patients. Annals of Family Medicine, 7, 47-55.

Richardson, J.L., Milam, J., McCutchan, A., Stoyanoff, S., Bolan, R., Weiss, J., Kemper, C., Larsen, R.A., Hollander, H., Weismuller, P., Chou, C.P., \& Marks, G. (2004). Effect of brief safer-sex counseling by medical providers to HIV-1 seropositive patients: A multi-clinic assessment. AIDS, 18, 1179-1186.

Schafer, J., Caetano, R., \& Clark, C. (1998). Rates of intimate partner violence in the United States. American Journal of Public Health, 88, 1702-1704.

Schumacher, J.A., Fals-Stewart, W., \& Leonard, K.E. (2003). Domestic violence treatment referrals for men seeking alcohol treatment. Journal of Substance Abuse Treatment, 24, 279-283.

Seltzer, M.L., Vinokur, A., \& Van Rooijen, L.J. (1975). A self-administered Short Michigan Alcohol Screening Test (SMAST). Studies on Alcoholism, 36, 117-126.

Sherman, L. W., Smith, D. A., Schmidt, J. D., \& Rogan, D. P. (1992). Crime, punishment, and stake in conformity: Legal and informal control of domestic violence. American Sociological Review, 57(5), 680-690.

Smith, P.H., Thornton, G.E., DeVellis, R., Earp, J.A., \& Coker, A.L. (2002). A population-based study of the prevalence and distinctiveness of battering, physical assault, and sexual assault in intimate relationships. Violence Against Women, 8, 1208-1232.

Spielberger, C.D. (1983). Manual for the State-Trait Anxiety Inventory. Palo Alto: Consulting Psychologists Press.

Spielberger, C.D., Sydeman, S.J., Owen, A.E., \& Marsh, B.J. (1999). Measuring anxiety and anger with the State-Trait Anxiety Inventory (STAI) and the State-Trait Anger Expression Inventory (STAXI). In M.E. Maruish (Ed.), The use of psychological testing for treatment planning and outcomes assessment (2nd ed., pp. 993-1021). Mahwah: Lawrence Erlbaum Associates. 
Stein, M., \& Kennedy, C. (2001). Major depressive and post-traumatic stress disorder comorbidity in female victims of intimate partner violence. Journal of Affective Disorders, 66, 133-138.

Stith, S.M., Smith, D.B., Penn, C.E., Ward, D.B., \& Tritt, D. (2004). Intimate partner physical abuser perpetration and victimization risk factors: A meta-analytic review. Aggression and Violent Behavior, 10, 65-98.

Straus, M.A., \& Gelles, R.J. (1990). Societal change and change in family violence from 19751985 as revealed in two national surveys. In M.A. Straus \& R.J. Gelles (Eds.), Physical violence in American Families (pp 507-526). New Brunswick, NJ: Transaction Publishers.

Straus, M.A. \& Gelles, R.J. (1990) Societal Change and change in family violence from 19751985 as revealed in two national surveys, in M.A. Straus and R.J. Gelles (Eds), Physical Violence in American Families (pp 507-526). New Brunswick, NJ Transaction Publishers.

Sudman, S., Bradburn, N.M., \& Schwarz, N. (1995). Thinking about answers : The application of cognitive processes to survey methodology (Jossey Bass Social and Behavioral Science Series). San Francisco: Jossey Boss.

Sutherland, C., Bybee, D., \& Sullivan, C. (1998). The long-term effects of battering on women's health. Women's Health, 4, 41-70.

Swanberg, J.E., Logan, T.K., \& Macke, C. (2005). Intimate partner violence, employment, and the workplace. Trauma, Violence, and Abuse, 6, 286-312.

Tjaden, P. \& Thoennes, N. (1998). Prevalence, incidence, and consequences of violence against women: Findings from the National Violence Against Women Survey. Washington, DC: National Institute of Justice and Centers for Disease Control and Prevention.

Vivian, D., \& Langhinrichsen-Rohling, J. (1994). Are bi-directionally violent couples mutually victimized?: A gender-sensitive comparison. Violence and Victims, 9, 107-124.

Ward, J.H. (1963). Hierarchical groupings to optimize an objective function. Journal of the American Statistical Association, 58, 236-244.

Zaza, S., Sleet, D.A., Thompson, R.S., Sosin, D.M., \& Bolen, J.C. (2001). Task Force on Community Preventive Services Reviews of evidence regarding interventions to increase use of child safety seats. American Journal of Preventive Medicine, 21 (Suppl. 4), 31-47.

Zung, W.W., Richards, C.B., \& Short, M.J. (1965). Self-rating depression scale in an outpatient clinic. Further validation of the SDS. Archives of General Psychiatry, 13(6), 508-515. 